\title{
CONSIDERAÇÕES SOBRE A CRÍTICA LITERÁRIA
}

JOÃO CEZAR DE CASTRO ROCHA reflete sobre as encruzilhadas do pensamento na universidade

0 .

Nas considerações aqui propostas, arrisco um panorama da crítica literária nas últimas décadas, concentrando-me em sua extração universitária. Em nenhuma circunstância pretendo oferecer um estudo exaustivo ou mesmo sistemático. Trata-se antes de oferecer um conjunto de ideias que certamente exigirão desenvolvimento ulterior. O propósito deste texto é tão-só provocar um debate que me parece urgente, a fim de reavaliar a estratégia dos professores e pesquisadores que se mantêm comprometidos com o entendimento do literário enquanto forma discursiva definida por complexas mediações com contextos históricos e discursivos.

1.

Parto de um princípio-chave: em seu conjunto, a universidade brasileira é a mais bem estruturada da América Latina. No continente, apenas a universidade mexicana é comparável. Contudo, no tocante ao sistema de bolsas (de iniciação científica à produtividade em pesquisa), aos órgãos federais e estaduais de incentivo à pesquisa e, sobretudo, no que se refere às formas de ingresso na carreira universitária, a universidade brasileira oferece condições de trabalho inigualáveis na América Latina.

(Reconhecê-lo é o primeiro passo para o desenvolvimento de uma nova atitude. É preciso abandonar certo tom melancólico e lamuriento, característico das conversas na hora do cafezinho. Identificar o alto nível de institucionalização da universidade brasileira não significa ignorar seus inúmeros problemas. No entanto, deixar de identificá-lo produz um círculo vicioso difícil de romper. Já sabemos que para transformar o 
mundo é preciso em primeiro lugar entendê-lo.)

E não apenas em relação aos países hermanos destaca-se a estrutura da universidade brasileira.

Não é recomendável para corações simples principiar a carreira na Itália ou na Alemanha. Como nesses países o sistema de cátedra ainda mantém alguma vigência, a ascensão profissional supõe o exercício resignado, por longos anos, de autêntica emasculação intelectual, pois é virtualmente impossível obter um posto universitário sem a chancela de um professor de prestígio. Na Itália, nos bons tempos de recursos, se não fartos, pelo menos existentes, vicejou a figura do ricercatore, que jamais chegaria a exercer formalmente uma cátedra, mas que se associava a um catedrático e podia passar a vida "pesquisando". Era o modelo do ricercatore a tempo indeterminato; título que vale como retrato de todo um sistema. $\mathrm{Na}$ Alemanha, a obrigação de escrever a temida Habilitationsschrift retarda, e muito, a possível independência do (talvez) futuro professor. Recorde-se que Walter Benjamin teve de renunciar à carreira acadêmica quando sua Habilitationsschrift, "Origem do Drama Barroco Alemão", foi simplesmente recusada pelo severo comitê - cujos membros, aliás, mergulharam numa meritória obscuridade.

Nesse horizonte rígido, a emasculação intelectual transforma-se em regra de convívio.

(É verdade que algo similar ocorre no Brasil, com o milagre da multiplicação de epígonos. Porém, é estruturalmente viável ser professor universitário no Brasil sem dobrar a espinha. A simples possibilidade significa muito.)

De igual modo, começar a trajetória acadêmica nos Estados Unidos implica sofrer as ansiedades do longo processo de uma "tenure-track position". Traduzindo: no estágio inicial da carreira, o "assistant professor" não possui estabilidade no emprego. Por isso, aproximadamente depois de seis anos de dedicação a uma determinada universidade, chega a hora de apresentar o seu "tenure case" - a linguagem jurídica é particularmente reveladora. Para que ele possa tornar-se "associate professor", ou seja, estável no trabalho, é preciso, 
idealmente, que seu nome seja aprovado unanimemente pelos colegas de departamento. E, claro, as avaliações dos alunos são fundamentais, pois, se forem negativas, a promoção ficará irremediavelmente comprometida. Isso para não mencionar que, em instituições de ponta, espera-se que o candidato já tenha produzido um "groundbreaking book", ainda que esteja no princípio da vida profissional. Além disso, o candidato deve participar de comitês. E desempenhar funções administrativas. E ensinar cursos que acompanhem the latest fashion na teoria contemporânea. E agradar a todos os colegas - ou a quase todos; certamente os mais importantes.

Etc. etc. etc.

Não é tudo.

Com a atual crise nos países europeus, muitos jovens professores, por exemplo, na Espanha, não mais dispõem da oportunidade de contar com estabilidade, pois seus cargos são temporários, renováveis a cada três ou quatro anos, e, em alguns casos, por um número limitado de vezes.

Uma consequência desse panorama é a crescente dependência em relação à agenda - usemos o termo! - de pesquisa favorecida pelas universidades e fundações norte-americanas, já que a obtenção de bolsas de prestígio e de cátedras temporárias representa uma alternativa concreta à mesquinhez da circunstância local. Se não me equivoco, esse é o caso de um país como a Argentina, cuja estrutura universitária foi desmontada pela ditadura militar e cujos salários são, para dizê-lo com alguma elegância, dramaticamente defasados. Basta conhecer os projetos de pesquisa de jovens professores (digamos entre os 35 e os 45 anos) para dar-se conta que seus estudos seguem à risca as tendências norteamericanas. E não por uma inesperada afinidade filosófica, mas por um gesto pragmático, buscando a inserção no circuito de verbas mais rico do planeta.

(É verdade que algo similar ocorre no Brasil, com a corrida de obstáculos para manter-se atualizado. Porém, é estruturalmente viável ser professor universitário no Brasil e desenvolver um projeto próprio de pesquisa. A simples possibilidade significa muito.)] 
Esclareço ainda mais minha perspectiva.

Uma das formas de resistência à ditadura militar foi o exercício diuturno do olhar crítico, a fim de trazer à superfície os limites e equívocos do regime. Desse modo, diagnosticou-se a falácia do milagre econômico, mesmo nos breves anos em que ele pareceu possuir alguma consistência; denunciou-se a teia de restrições progressivas às liberdades civis, apesar da aparência de legalidade buscada pelo regime; advertiu-se o caráter de política de Estado na prática de tortura aos presos políticos, ainda que os generais terminantemente a negassem; enfim, a vigilância crítica chegou a converter-se numa ética própria. Em tal horizonte, a possibilidade de reconhecer eventuais avanços, em qualquer área, significava renunciar à tarefa de enfrentar a ditadura. Assim, a crítica tornou-se instrumento precioso, não apenas como uma atitude inerente à atividade intelectual, porém sobretudo como uma forma prática da luta pelo retorno à democracia.

Pergunto-me se a mesma ética ainda pode produzir resultados igualmente fecundos. O contexto mudou dramaticamente nas últimas décadas, quase não é preciso lembrá-lo, porém uma dificuldade similar persiste: como se identificar a excepcionalidade do sistema universitário brasileiro na América Latina, e mesmo em relação a determinados países europeus, representasse uma demissão do pensamento crítico; como se apontar o alto nível de institucionalização da pós-graduação fosse um gesto oportunista ou, para tudo dizê-lo numa palavra, alienado.

Proponho entender a circunstância atual pelo avesso. Isto é, devemos partir do reconhecimento das conquistas reais da última década e, ao mesmo tempo, precisamos assinalar os inúmeros problemas que se mantêm presentes na universidade brasileira. Essa mudança de estratégia permitiria destacar o fato estrutural decisivo: em 2014, é possível pensar-se numa carreira acadêmica de longo prazo alheia aos constrangedores rituais de beija-mão exigidos pelos códigos rígidos da endogamia.

(A universidade brasileira finalmente reúne condições estruturais para deixar de ser uma sucursal mais ou menos provinciana do Salão dos Verdurin.) 
2.

Os oito anos do governo Lula contribuíram, e muito, para solidificar esse panorama e mesmo para dar um relevante passo adiante. A CAPES e o $\mathrm{CNPq}$ tiveram seus recursos consideravelmente ampliados, o que permitiu incrementar o número de pesquisadores do CNPq, uma antiga reivindicação.

(De igual modo, no Rio de Janeiro, onde trabalho e pesquiso, a FAPERJ conheceu avanços fundamentais durante o governo Sérgio Cabral, ampliando, e muito, os programas de apoio à pesquisa.)

Ademais, a criação de universidades federais e a transformação de escolas técnicas federais em centros universitários possibilitaram uma absorção inédita de doutores recém-formados, ajudando a resolver um problema que já se tornava crônico, especialmente nos grandes centros urbanos, cujas universidades não tinham condições de assimilar os doutores formados em seus cursos de pós-graduação.

Reitero que não pretendo travestir-me num anacrônico Dr. Pangloss do sistema universitário brasileiro! Todas essas iniciativas apresentam problemas e impasses, desde as precárias condições de infraestrutura básica à ausência de bibliotecas, mas, ao mesmo tempo, elas abriram oportunidades para a inserção de jovens doutores inexistentes em outros sistemas universitários - esse é o ponto que se deve destacar.

\section{Por quê?}

Por uma razão simples: estruturalmente, é viável no Brasil, hoje, em 2014, desenvolver uma carreira acadêmica digna e, ao mesmo tempo, manter uma razoável autonomia intelectual. Isto é, nada obriga um jovem pesquisador a aderir a este ou aquele grupo, a subordinar-se a este ou aquele credo. Sem dúvida, é mais cômodo colocar-se à sombra de nomes consagrados ou no âmbito de redes bem estabelecidas; porém, estruturalmente, é possível recusar essa previsível trajetória.

Nem sempre foi assim: o epigonismo e a endogamia já foram a mola real do sistema universitário brasileiro. 
(Contudo, recorde-se a lição sempre atual de Graciliano Ramos: liberdade absoluta ninguém desfruta; começamos aprisionados pela gramática e, de uma hora para outra, descobrimo-nos encarcerados literalmente.)

No início da implantação dos programas de pós-graduação no Brasil, havia poucos doutores habilitados para orientar mestrandos e doutorandos. Por isso, muitos nomes reconhecidos começaram seus cursos de mestrado e doutorado já como professores de prestígio, alguns com obras de referência publicadas. Somente após entregarem suas teses, puderam orientar alunos.

Ainda assim eram poucos.

Muito poucos.

E, sobretudo, todos sabiam disso.

Daí o comportamento autoritário e idiossincrático de muitos dos mestres nos anos 70 e ainda nos 80 . Tudo era muito claro: escrever uma tese com A implicava afastar-se irremediavelmente de B; e o mesmo era verdadeiro para as opções teóricas e a definição do horizonte de leitura. A tradição autoritária, tipicamente brasileira, não ajudou em nada, apenas colaborando para o reforço de práticas que, felizmente, se tornaram vetustas, caricatas até. Alguns velhos mestres ressentem-se, nostálgicos, mas somente temos motivos para celebrar essa transformação decisiva.

A ironia cortava fundo: com maior ou menor grau de envolvimento, uma boa parte dos professores universitários se opunha à ditadura militar, correndo riscos e sofrendo as consequências de sua posição. A eles, todo o respeito é devido. No entanto, alguns reproduziam nas salas de aula $\mathrm{o}$ comportamento autoritário que criticavam nos discursos e nos atos políticos.

O repertório de leitura, sempre limitado, relacionava-se à posição teórica abraçada pelo mestre; isso para não mencionar a simples eliminação de toda forma literária alheia ao método hermenêutico por ele defendido; a intolerância completa com qualquer forma alternativa de pensar a 


\begin{tabular}{ll|l}
\hline celeuma & número 4 | maio 2014 & dossiê \\
\hline
\end{tabular}

literatura. Preciso acrescentar algo? À diferença do alferes Jacobina, o autoritarismo não exige o uso de farda. O espelho é o controle sobre o outro, no caso, os alunos.

(Ana Cristina César tinha toda razão ao protestar, não contra a disciplina teoria da literatura, mas contra a forma totalitária de ensinála.)

Uma vez conseguido o título de "Doutor", a etapa seguinte para o futuro jovem professor não era fácil; os empregos eram escassos e as poucas posições disponíveis nos grandes centros costumavam ser ocupadas pelos melhores alunos dos professores dessas mesmas instituições. A margem de manobra era pequena; na verdade, praticamente não havia margem alguma, pois a opção de principiar a carreira fora de seus eixos de origem ainda não era tão comum quanto hoje em dia.

Nesse cenário incipiente, em que a pós-graduação começava a se articular, a endogamia se impôs como um dado, por assim dizer, natural. Além disso, e é importante recordá-lo, na América Latina, universidades como a UBA, na Argentina, a UNAM, no México, e a USP historicamente assumiram a relevante missão de atrair vocações, constituindo uma série de ritos de passagem que favoreceram a permanência na instituição dos alunos mais talentosos. Desse modo, pretendia-se fortalecer os sistemas universitários através da absorção dos jovens pesquisadores de maior promessa.

Em outras palavras, não se trata de condenar a endogamia com base num princípio abstrato, por definição insuficiente para o estudo de um sistema concreto, mas de assinalar seus limites nas atuais circunstâncias da universidade brasileira.

3.

E ainda não é tudo.

O fortalecimento do sistema de pós-graduação ocorreu durante os anos da ditadura militar, que, a partir do AI-5, e sobretudo durante o governo Médici, tornou a tortura uma política de Estado, levando a repressão nas 


\begin{tabular}{l|ll}
\hline celeuma & número $4 \mid$ maio 2014 & dossiê \\
\hline
\end{tabular}

artes e no pensamento a níveis que nem mesmo o famigerado DIP sonhara. A universidade foi muito prejudicada, e não apenas nos expurgos de alguns de seus principais nomes, mas também no dia a dia da sala de aula, nas decisões de temas de pesquisa, no cotidiano dos departamentos, na presença ostensiva de agentes de segurança nos corredores; enfim, esse foi outro tempo de homens partidos.

Nesse contexto, a escolha de métodos de leitura ou de abordagens teóricas revestiu-se de uma tensão particular, provavelmente inimaginável nos dias atuais. Pois ler a X ou a Y, refletir com base em A ou $\mathrm{B}$, também não deixava de ser uma forma de posicionar-se em relação à ditadura, à repressão crescente, à luta armada. Hoje, à distância, talvez se possa considerar tal atitude problemática, excessiva até, porém, no calor da hora, a questão possuía uma urgência que não deve ser negligenciada, sob pena de desentender as polêmicas que marcaram o período. Afinal, nem sempre o anacronismo é bom conselheiro.

Por isso, as querelas metodológicas e teóricas que marcaram os anos 70 e 80 são indissociáveis desse panorama mais amplo e devem ser relidas nesse âmbito.

Posso dizê-lo com mais clareza: escrevi um livro dedicado à reconstrução do célebre cisma dos anos 40 entre cátedra e rodapé, no qual mostrei que as versões dominantes sobre o episódio são anacrônicas[1]. Mais: autoindulgentes, adotando, com louvável ingenuidade, o ponto de vista da universidade para tratar de um momento em que, pelo contrário, as faculdades de letras ainda não estavam configuradas tais como as entendemos hoje em dia.

No curso dessa pesquisa, surpreendi-me com a vitalidade da crítica literária produzida na universidade nos anos 70 e 80. Dominante nesse período, identifiquei um gesto que propus denominar "sistema interno de emulação".

Trocando em miúdos: a rivalidade de métodos e de teorias levou a um cruzamento estratégico de autores e obras. 
Um único exemplo: o grupo comprometido com a pesquisa da cultura nacional privilegiou o estudo de Mário de Andrade, enquanto o grupo interessado em experimentalismos linguísticos valorizou a obra de Oswald de Andrade. As fronteiras podiam ser porosas, pois nada impedia que um professor da PUC-SP escrevesse sobre Mário de Andrade, ou que um pesquisador da USP refletisse sobre Oswald de Andrade. A porosidade era fundamental, pois o que estava em jogo era a demonstração pública do rendimento desse ou daquele olhar crítico. A Unicamp, com seu projeto institucional singular, tornou o campo ainda mais complexo, vale dizer, mais fecundo e propício à proliferação de memoráveis debates, já que o jogo dialético entre forma literária e processo social complicava cômodas dicotomias.

Isso em São Paulo.

No Rio de Janeiro, em menor proporção, a polêmica envolvia mais diretamente a PUC-RJ e a UFRJ, em bases similares, embora com suas especificidades. A PUC-RJ, com quatro ou cinco nomes de ponta, e todos com orientações diversas, não possuía uma homogeneidade comparável à da PUC-SP. Além disso, a UFRJ possuía o empenho nacional bem representado por Afrânio Coutinho, mas também abraçava uma linha filosófica, liderada por Eduardo Portella.

(Limito-me, como se vê, ao eixo Rio-São Paulo. De fato, um dos aspectos mais importantes da crítica universitária foi o surgimento em todo o país, especialmente a partir dos anos 90 , de centros de excelência com orientação própria.)

A vitalidade dos anos 70 e 80 dependeu da marcação firme de posições adversárias e, sobretudo, se nutriu do enfrentamento franco, por vezes ríspido, entre os representantes de grupos contrários. Não importa: o que de fato conta é que, a fim de melhor refutar o oponente, o sistema interno de emulação exigia a leitura cuidadosa da obra alheia.

Vale dizer: a leitura cuidadosa de abordagens diversas se impunha, ainda que se tratasse de uma leitura com dentes afiados. 
Ao fim e ao cabo, o busílis era bem diferente (afinal, estávamos nos anos 70): a crítica literária importava!

Daí a força do paradigma leituras em competição, na expressão de Roberto Schwarz. Esse foi o seu grande momento histórico. E era isso mesmo: competição entre formas adversárias de entendimento do literário, isto é, conflito entre modos opostos de visão do mundo. (Noel Rosa, por um breve momento, tornou-se crítico literário: Quem dá mais?)

4. Pois bem.

E por que a crítica literária importava tanto?

A geração que assumiu postos universitários no final dos anos $60 \mathrm{e}$ durante os anos 70 foi provavelmente a última cuja formação foi fundamentalmente literária, muito embora o cinema já tivesse sido incorporado como experiência estética e crítica. Essa geração chegava à universidade com um repertório de leituras considerável - e isso dos clássicos aos contemporâneos. Portanto, a experiência da leitura era bem proustiana, formadora no sentido pleno da palavra.

Daí a relevância propriamente existencial da crítica literária, e esse dado ajuda a entender a vitalidade e a virulência das polêmicas do período. Não se tratava, como se tornou dominante a partir dos anos 90, apenas de uma questão epistemológica. Pelo contrário, o que estava em jogo era toda uma forma de convívio.

Porém, a partir de final dos anos 70 ou, digamos, meados da década seguinte, a cada nova geração de alunos de pós-graduação e, portanto, de futuros professores, a literatura passou a competir com outros meios de (in)formação. Deveria dizer: passou a perder espaço para outros meios de (in)formação. Em consequência, o repertório de leitura reduziu-se substancialmente, acompanhando o eclipse da presença da literatura no dia a dia. Mais recentemente, o processo radicalizou-se e chegou às salas de aula; agora, a literatura mesma tem sido deslocada por outros objetos de estudo no ensino e nas pesquisas de jovens professores. 


\begin{tabular}{l|l|l}
\hline celeuma & número $4 \mid$ maio 2014 & dossiê \\
\hline
\end{tabular}

Meios de comunicação e objetos de estudo em competição.

(A pluralização do conceito de literatura é a contrapartida positiva dessa circunstância - reservo, porém, o tema para outra ocasião.)

Esse é um fenômeno contemporâneo por excelência, cujos primórdios remontam pelo menos ao fim da Segunda Guerra Mundial. Refiro-me à perda progressiva da centralidade da literatura na transmissão de valores culturais e, sobretudo, na vanguarda das discussões do momento.

Na elaboração e na crítica de visões do mundo - portanto.

Para tudo dizer: locus privilegiado da Bildung.

Em alguma medida, nos anos 70 e 80, o sistema interno de emulação executou um surpreendente réquiem da centralidade do literário no universo letrado brasileiro; reduzido, diminuto mesmo, mas nem por isso menos ativo. Sem que seus participantes necessariamente o soubessem, os embates radicais nos anos 70 e 80 marcaram o epílogo de uma história propriamente literária.

Talvez aí resida uma chave para entender a fragmentação ocorrida no campo universitário a partir dos anos 90, acentuada a partir da primeira década deste século. Tal fragmentação se caracteriza pela presença de grupos de pesquisa que desenvolvem de modo relativamente autônomo seus próprios métodos e perspectivas teóricas, valorizando muito mais a inserção internacional do que o debate local. É dupla a base dessa fragmentação: de um lado, a pluralidade, aparentemente incontrolável, de formas de definir a experiência literária; de outro lado, a ampliação, aparentemente infinita, dos objetos de estudos.

Ora, como a literatura definitivamente perdeu a centralidade - aliás, nas condições peculiares da formação brasileira, tal centralidade constituiu um caso especial -, o sistema interno de emulação, que pressupõe o espaço público para a discussão dos contrários, tende a ser substituído pelo surgimento de centros de excelência em boa medida autocentrados. 


\begin{tabular}{l|l|l}
\hline celeuma & número $4 \mid$ maio 2014 & dossiê \\
\hline
\end{tabular}

Há mais.

A consolidação e a expansão do sistema de pós-graduação; o número crescente de doutores; o aumento nas verbas de pesquisa; a internacionalização muito bem-vinda da universidade brasileira; ora, se vejo bem, todos esses fatores têm estimulado a criação de poderosas redes de pesquisa, fortalecidas por contatos com a produção internacional.

Em palavras direitas: ao contrário do que ocorria nos anos 70 e 80 , por exemplo, professores interessados na perspectiva dos estudos culturais não precisam mais debater com os adversários, a fim de legitimar sua opção. E isso simplesmente porque as condições novas de institucionalização da universidade brasileira permitem uma circulação plena de seus trabalhos no interior do mesmo grupo - aí incluídos, claro está, os pares em universidades estrangeiras. As publicações interinstitucionais proliferam; os convênios asseguram o intercâmbio sem o ônus de desgastantes polêmicas no mesmo campo de forças; por isso mesmo, os congressos temáticos multiplicam-se, sempre com um algarismo romano após o título charmoso, pois a promessa de continuidade faz toda a diferença nos tempos voláteis que correm.

Eis o paradoxo tornado método: trata-se de uma endogamia que pula a cerca para não sair de casa.

Reitero um elemento que se impõe nessa nova constelação: o dado comum à maioria desses centros de pesquisa é a preocupação com formas plurais de compreensão da literatura, assim como o privilégio de outros modos de articulação de sentido, quase sempre audiovisuais e digitais.

\section{5.}

A crise tão propalada da crítica literária tanto expressa o esgotamento de certa concepção, quanto representa um crescimento institucional.

Os dois fenômenos são simultâneos.

Crise de crescimento: o alto nível de institucionalização da universidade brasileira permitiu o surgimento de grupos de pesquisa que, por assim 
dizer, se bastam a si mesmos, compensando o possível isolamento local através de uma inserção internacional sempre crescente. O dado desconcertante é que a preocupação com a forma literária cedeu lugar à atenção com outros modos de articulação de sentido.

Tal tendência é irreversível.

Esgotamento: a perda definitiva da centralidade do literário acarreta, como consequência principal, a necessidade de superar o modelo leituras em competição. Esse modelo supunha uma definição mais ou menos consensual de literatura e, sobretudo, dependia do acordo dos demais grupos sobre sua relevância.

Tais condições pertencem ao passado recente da cultura.

Ora, a polarização “direita/esquerda”, característica da Guerra Fria, perdeu muito de sua força; a ditadura militar deu lugar ao período democrático de maior longevidade na história política brasileira; há dez anos um partido de esquerda encontra-se no poder; a universidade brasileira conheceu um grau inédito de institucionalização. Por fim, o campo literário teve seu alcance drasticamente reduzido, tanto pela marginalização da literatura, quanto pela dispersão dos pesquisadores a ela dedicados.

Nesse cenário algumas perguntas tornam-se necessárias.

Continuaremos a discutir eternamente as diferenças dos nossos mestres? Estaremos condenados ao eterno retorno das questões dos anos 70 e 80 ? Seremos incapazes de imaginar novos problemas, abordagens e objetos? Não saberemos estar à altura dos desafios que a situação contemporânea impõe?

Na verdade, já passou da hora de reavaliar certos embates que se arrastam desde os anos 70 e cuja permanência constrange a criatividade dos professores formados a partir dos anos 90 .

Exemplar da circunstância do final dos anos 60 e da década seguinte foram os debates calorosos sobre o modernismo e seus líderes; discussão 
que se encontrava na ordem do dia nas comemorações do cinquentenário da Semana de Arte Moderna. Mário ou Oswald; o próprio ou o alheio; a pesquisa da cultura ou a experimentação semiótica? As posições eram radicais, e trincheiras definitivas foram cavadas; no entanto, ninguém questionava a centralidade do modernismo e da experiência literária.

Isto é, o modelo leituras em competição supõe uma área comum de interesses, fornecendo a moldura que torna os debates significativos.

Eis precisamente o que se perdeu: um território mais ou menos homogêneo; continente cuja promessa de conquista permitia reunir adversários de velha data.

A universidade brasileira transformou-se num autêntico Caribe: vivemos cercados de ilhas por todos os lados; algumas são ilhas de excelência, reconheça-se.

Contudo, nem sequer dispomos de um arquipélago: puras ilhas. John Donne reescrito: uma ilha é só uma ilha.

6.

$\mathrm{Na}$ ausência das condições que estimulavam a competição entre leituras, retornamos à pergunta programática: o que fazer?

Uma ideia: a fim de seguir adiante, reler os debates das últimas décadas e tomar decisões claras.

E à luz do dia.

Os debates dos anos 70 e 80 que ainda hoje se arrastam revelam, sem disfarce, que pelo menos três gerações de jovens doutores se resignaram ao papel pálido de epígonos, medindo suas ambições intelectuais pelo latitude do sorriso do mestre.

Nas atuais condições estruturais da universidade brasileira, porém, o epigonismo deixou de ser caminho único; trata-se antes da demissão da tarefa de pensar por si mesmo. Ora, não é possível deixar de imaginar 
polêmicas novas, com base nas condições complexas do presente que nos cabe entender.

Para tanto, deveríamos reler os debates e alcançar certo nível de consenso que permitisse considerar quais são os problemas críticos efetivamente resolvidos pelas refregas anteriores. Tal consenso obrigaria a uma revisão das práticas atuais, estimulando a formulação de novas perguntas.

Dou um exemplo que me envolve; pois, quem semeia vento, deve deixar o guarda-chuva no armário.

Em 1977, Roberto Schwarz lançou Ao vencedor, as batatas. Seu livro foi o primeiro esforço sistemático de contestação de uma tradição crítica dominante já em vida do próprio Machado de Assis.

Ninguém expressou tal tradição (equivocadíssima, diria José Dias, crítico acidental) com a eloquência de Sérgio Buarque de Holanda. Em Raízes do Brasil, ele escreveu: "Machado de Assis foi a flor dessa planta de estufa" [2]. A estufa era o deliberado alheamento da elite letrada em relação à sociedade brasileira. $\mathrm{O}$ autor de $\mathrm{O}$ alienista teria sido o representante maior dessa tendência. Se um autor com a formação literária e a acuidade crítica de um Sérgio Buarque caiu nessa esparrela, o que não dizer da média dos críticos e professores universitários?

(En passant: esse entendimento, que já nasceu torto, ajudou a engendrar um dos mais insossos "Remo-Paissandu" das letras pátrias: Machado de Assis ou Lima Barreto?)

Pois bem.

A obra de Roberto Schwarz efetivamente resolveu esse problema crítico. Após seu livro inicial, aprofundado em 1990 com Um mestre na periferia do capitalismo, se alguém insistir na velha tecla do absenteísmo machadiano revela ignorância ou simplesmente má-fé.

Quero dizer: é claro que se pode discordar deste ou daquele aspecto da leitura de Schwarz, pode-se pensar em outro modo de abordagem do 
literário etc. etc., mas não se pode, com o mínimo de honestidade intelectual, negar que o autor de Duas meninas acrescentou ao debate argumentos decisivos que permitem reconhecer de maneira inequívoca a forma propriamente machadiana de lidar com a circunstância histórica do Brasil escravocrata.

E ponto final.

Recordo ainda, brevemente, mais um exemplo, em outro espectro crítico, para que não se veja meu raciocínio como partidário - aliás, exemplo que também me inclui.

Os irmãos Haroldo e Augusto de Campos e Décio Pignatari assumiram a tarefa de reavaliar o legado de Oswald de Andrade.

Como se sabe, por décadas, formulou-se um juízo muito desfavorável ao trabalho poético e crítico de Oswald, cuja personalidade passou a ser considerada como sua verdadeira obra de arte total, em detrimento de seus textos. Isso para não mencionar sua poesia, sumariamente descartada por mais de uma geração.

Os estudos de Haroldo de Campos resolveram efetivamente esse problema crítico. Depois de sua leitura, se alguém insistir na velha tecla da insuficiência artística oswaldiana revela ignorância ou simplesmente máfé.

Quero dizer: é claro que se pode discordar deste ou daquele aspecto da leitura de Haroldo de Campos, pode-se pensar em outro modo de abordagem do literário etc. etc., mas não se pode, com o mínimo de honestidade intelectual, negar que o autor de Galáxias acrescentou ao debate argumentos decisivos que permitem reconhecer de maneira inequívoca o alcance da obra de Oswald de Andrade.

E ponto final.

7.

A primeira tarefa, portanto, seria a de construir um consenso mínimo, independentemente de grupos, credos ou afinidades. 
A opção menos desafiadora é reconhecer que o reino encantado da endogamia transformou irremediavelmente a universidade numa sucursal provinciana do "pequeno núcleo" dos Verdurin, com seus códigos caricatos e seu repertório cultural limitado. A descrição do narrador proustiano cai como uma luva para entender a endogamia acadêmica: “Para fazer parte do 'pequeno núcleo' do 'pequeno grupo', do 'pequeno clã' dos Verdurin, bastava uma condição, mas esta indispensável: aderir totalmente a um credo (...)”.[3]

Uma pergunta simples permite fugir desse espectro: quais são os problemas críticos efetivamente resolvidos no âmbito das polêmicas dos anos 70 e 80 ?

Há muitos, e chegou a hora de identificá-los - mencionei apenas dois exemplos, o leitor deste texto certamente pensará em outros e assim começamos a escapar do círculo vicioso.

Num segundo momento, e a partir da construção desse consenso crítico, a tarefa se transforma: trata-se de seguir adiante, formulando novos problemas.

Novos, eu disse, isto é, não vale ficar à sombra de nomes consagrados ou de redes de contato bem estabelecidas.

E, de igual modo, há muitas questões a serem inventadas.

Volto aos exemplos que me envolvem na discussão.

Uma vez que o problema relativo ao absenteísmo machadiano foi superado, outros desafios críticos podem ganhar direito pleno de cidadania.

De fato, ainda não dispomos de estudos minuciosos acerca do conjunto dos procedimentos compositivos textuais propriamente machadianos a noção de "narrador volúvel", proposta por Roberto Schwarz na caracterização do defunto autor, é um caminho promissor, mas precisamos ampliar esse tipo de descrição para o restante da vasta obra 
de Machado[4]. Penso em procedimentos textuais específicos: como a frase machadiana se transformou ao longo das cinco décadas de sua produção? Em relação aos temas, é possível identificar obsessões do autor, assim como as transformações ocorridas no tratamento de temas dominantes? A apropriação machadiana da tradição desenvolveu um ritmo singular? Em caso afirmativo, como compreendê-lo?

(A pergunta mais importante: como explicar que as gerações mais jovens ainda não tenham enfrentado esses problemas?).

Oswald de Andrade apresenta um desafio similar.

Isto é, uma vez que o problema relativo à importância da obra oswaldiana foi superado, outros desafios críticos podem ganhar direito pleno de cidadania.

De fato, ainda não dispomos de estudos minuciosos acerca de um aspecto intrigante de $A$ crise da filosofia messiânica - a suma antropofágica oswaldiana. Ora, como é possível que Oswald conclua seu ensaio com uma surpreendente equação que localiza a utopia do bárbaro tecnizado nos Estados Unidos? Ainda mais: como é possível que o cozinheiro das almas deste mundo tenha considerado a James Burnham o modelo de antropófago para o futuro da humanidade? Autor do constrangedor manual de autoajuda corporativa, The Managerial Revolution, publicado em 1941, o autor norte-americano, pelo avesso, foi importante fonte para a escrita de 1984. Mas, ao contrário da percepção crítica de George Orwell, Oswald endossou as teorias de Burnham!

Por quê?

Como transformar o evidente tropeço oswaldiano em acicate para o pensamento?

(A pergunta mais importante: como explicar que as gerações mais jovens ainda não tenham enfrentado esse problema?).

É preciso descobrir novos caminhos.

Contudo, em nenhuma circunstância, proponho que todos os gatos 
sejam pardos na noite eterna das ideias mal digeridas. É claro que nem todas as leituras são equivalentes, e é ainda mais óbvio que certas leituras saltam aos olhos como mais interessantes e provocadoras do que outras. A aderência ao texto segue sendo um critério seguro.

O debate que procuro estimular é outro: no campo das letras, não há mais "vencedores" possíveis; a disputa, hoje, ocorre num campo minado e, sobretudo, muito, mas muito reduzido.

O ponto de fuga se perdeu.

Aprenderemos a ler com olhos cubistas ou estaremos condenados a contemplar o próprio umbigo.

Chegou a hora de mudar de paradigma.

Trata-se de investir na complexidade das leituras alternativas; colocá-las em confronto, entendendo que abordagem alguma esgota a riqueza de autores como Machado de Assis, Oswald de Andrade, Clarice Lispector, Guimarães Rosa. As diferenças serão realçadas precisamente porque abandonaremos a ideia voluntarista de provar que minha hipótese é a forma de leitura mais adequada.

8. Mencionei minha proposta de consenso crítico relativo a aspectos das obras de Machado de Assis e Oswald de Andrade.

Ora, questões semelhantes podem ser imaginadas, literalmente, para toda a literatura brasileira. Especialmente em relação à produção contemporânea.

Para tanto, o primeiro passo é reconhecer a necessidade de inventar problemas que não foram propostos pelos nossos mestres.

Em algum momento, precisaremos arriscar esse gesto.

(Recorde-se a lição de Platão em O Sofista: o parricídio é o motor do pensamento.) 
[1] Crítica literária: em busca do tempo perdido? Chapecó: Argos, 2011.

[2] Sergio Buarque de Holanda. Raízes do Brasil. São Paulo: Companhia das Letras, 2002, p. 162.

[3] Marcel Proust. Em busca do tempo perdido. Volume I. No caminho de Swann. Tradução de Mário Quintana. São Paulo: Editora Globo, 2011, p. 253.

[4] Em meu último livro, Machado de Assis: por uma poética de emulação (Rio de Janeiro: Civilização Brasileira, 2013), tentei enfrentar esse desafio.

JOÃo CEZAR DE CASTRO ROCHA é professor de literatura da Universidade do Estado do Rio de Janeiro e autor, entre outros, de Crítica literária: em busca do tempo perdido? (Argos) e Machado de Assis: por uma poética de emulação (Civilização Brasileira) 